\title{
Phonological processes and the perception of phonotactically illegal consonant clusters
}

\author{
MARK A. PITT \\ Ohio State University, Columbus, Ohio
}

\begin{abstract}
The perception of consonant clusters that are phonotactically illegal word initially in English (e.g., $/ \mathrm{tl} /, / \mathrm{sr} /$ ) was investigated to determine whether listeners' phonological knowledge of the language influences speech processing. Experiment l examined whether the phonotactic context effect (Massaro \& Cohen, 1983), a bias toward hearing illegal sequences (e.g., /tl/) as legal (e.g., /tr/), is more likely due to knowledge of the legal phoneme combinations in English or to a frequency effect. In Experiment 2, Experiment 1 was repeated with the clusters occurring word medially to assess whether phonotactic rules of syllabification modulate the phonotactic effect. Experiment 3 examined whether vowel epenthesis, another phonological process, might also affect listeners' perception of illegal sequences as legal by biasing them to hear a vowel between the consonants of the cluster (e.g., /tolæ/). Results suggest that knowledge of the phonotactically permissible sequences in English can affect phoneme processing in multiple ways.
\end{abstract}

An overarching goal of research in psycholinguistics is to delineate the structure and flow of information through the language processing system. A popular method of addressing this issue is to investigate how different types of linguistic information interact during processing. Interaction has been explored in areas ranging from the integration of semantic and syntactic information in sentence and discourse processing (Altman, Garnham, \& Dennis, 1992; Boland, 1997; Boland \& Cutler, 1996; MacDonald, Pearlmutter, \& Seidenberg, 1994) to local contextual influences in phoneme processing.

Research on contextual effects in phoneme perception has been quite varied, including demonstrations of visual and auditory cue integration in phoneme identification (McGurk \& MacDonald, 1976; Massaro, 1987), perceptual compensation in phoneme processing as a result of coarticulation differences from the preceding segment (Mann \& Repp, 1981; Repp \& Mann, 1981), and lexical and phonological influences on phoneme identification (Connine, Blasko, \& Wang, 1994; Massaro \& Cohen, 1983; Pitt \& Samuel, 1995; Samuel, 1996). The present investigation focused on the last of these.

A number of researchers have argued that the phonology of a language is a rich source of information that could be exploited to facilitate auditory word recognition (Church, 1987a, 1987b; Frauenfelder \& Lahiri, 1989; Frazier, 1987; Gaskell, Hare, \& Marslen-Wilson, 1995). The case that is made in favor of this position is that much

I thank Lisa Shoaf and Katherine Smith for assistance in many phases of this project. Jim Flege, Michael Brent, and an anonymous reviewer provided many helpful comments on an earlier version of the paper. This research was supported by Grant R29-DC01774 from the National Institute on Deafness and Other Communication Disorders. Correspondence should be addressed to M. A. Pitt, Department of Psychology, 1885 Neil Ave., Columbus, OH 43220 (e-mail: pitt.2@osu.edu). of the phonological variability in speech production is lawful and can be understood by consulting the phonology of the language. For example, vowels in unstressed syllables (e.g., schwa) can be deleted in spoken words, sometimes creating strings with phonotactically illegal sequences (e.g., tomorrow $\rightarrow$ tmorrow). Knowledge of English phonotactics could be used to recognize that $/ \mathrm{tm} /$ is not a permissible word-initial sequence. The intended vowel could then be recovered, leading to successful recognition of the word. Thus, phonological knowledge, like other forms of linguistic information (e.g., lexical) could aid word processing.

Increasing experimental evidence suggests that phonological knowledge is indeed used during recognition. Lahiri and Marslen-Wilson (1991) showed that listeners' responses in a gating task were predictable on the basis of the role a phonetic cue serves in the language. Vowel nasalization is nondistinctive in vowels in English. When such a vowel is heard without the next phoneme, English listeners will guess that the following consonant is a nasal. In Bengali, vowel nasalization is distinctive, making the identity of the following consonant (e.g., nasal or stop) unpredictable. Gaskell and Marslen-Wilson (1996; see also Gaskell et al., 1995) have reported related work in which the recognition system appears to compensate for place assimilation in speech production by applying knowledge of English phonology. Reaction times in an auditory-visual repetition priming task were equally fast when the prime was pronounced correctly (e.g., lean in lean bacon) or with the place of articulation of the nasal the same as the onset of the following word (e.g., leam in leam bacon). These results suggest that the lexical representation of lean was activated equally well by both primes. Importantly, there was a slowdown $(21 \mathrm{msec})$ in response time when the mispronounced prime was presented in an unviable context, in which the nasal did not assimilate to 
the place of articulation of the following stop (e.g., leam game). Gaskell and Marslen-Wilson entertained the idea that phonological processes "inferred" the intended place of articulation when assimilation was viable (e.g., "leam bacon").

Findings from other studies suggest that a listener's knowledge of the phonotactics of English (permissible phoneme combinations) influence speech perception. Jusczyk, Friederici, Wessels, Svenkerud, \& Jusczyk (1993; Jusczyk, Luce, \& Charles-Luce, 1994; see Jusczyk, 1995, for a review) found that infants developed a preference for phoneme sequences in their native language at 9 months of age, but showed no such preference at 6 months. Cutting (1975; Cutting \& Day, 1975) noted that phonotactically illegal sequences were never reported by listeners in phonological fusion experiments, in which a pair of words is presented dichotically and listeners must report what was heard. For example, pay was presented to the left ear and lay to the right. When the percepts fused, they were heard as play, never as lpay, which suggests that listeners' knowledge of English phonotactics influenced how the words blended.

Of particular relevance to the present study are data reported by Massaro and Cohen (1983; see also Brown \& Hildum, 1956; Flege \& Wang, 1989). Listeners had to categorize steps along a $/ r /-/ 1 /$ continuum as either $/ r /$ or 11/. Each step was embedded in a consonant (obstruent) context so that the liquid formed the second consonant of a two-consonant cluster (e.g., / tri/). In the conditions of interest, the context phonemes were chosen so that the cluster formed at one endpoint of the continuum was phonotactically legal at the beginnings of words (e.g., $/ \mathrm{dr} /, / \mathrm{sl} /, / \mathrm{tr} /)$ and at the other endpoint it was illegal (e.g., $/ \mathrm{dl} /, / \mathrm{sr} /, / \mathrm{tl} /)$.

Listeners' classification responses showed a bias in favor of legal sequences. Steps at the /1/ endpoint were identified frequently as $/ \mathrm{r} /$ when preceded by $/ \mathrm{t} /$ but never as $/ r /$ when preceded by $/ s /$ Just the reverse was found at the $/ r /$ end of the continuum: Steps tended to be heard as $/ 1 /$ when preceded by $/ \mathbf{s} /$, but as $/ \mathrm{r} /$ when preceded by $/ \mathrm{t} /$. Curiously, the /d/ context, which might have been expected to produce an $/ r /$ bias equivalent to that of $/ t /$, showed minimal effects of phonotactic legality (Massaro \& Cohen, 1983; Experiment 3).

Because labeling in the $/ \mathrm{s} /$ and $/ \mathrm{t} /$ contexts was always toward a legal sequence, one interpretation of these findings is that knowledge of the phonotactic constraints of English (i.e., rules of permissible phoneme combinations) affected processing of the liquid. An equally plausible (though not mutually exclusive) interpretation is that the results were due to the frequency with which the cluster occurs in the language. This can be thought of as an extreme version of a frequency effect, in which illegal clusters never occur word initially in English.

Although the first interpretation invokes a linguistically based mechanism to explain the outcome, no such commitment is required of the latter interpretation. The context effect might be no more than another demonstra- tion of a general frequency effect, not the reflection of a process specific to language. Furthermore, even if the effect is specific to language processing, phonological processing per se is not necessary to produce the phonotactic context effect. The TRACE model of word recognition can simulate the phenomenon without relying on explicitly stored knowledge about English phonology (McClelland \& Elman, 1986; see also McClelland, 1991; Massaro, 1989). The bias toward perceiving legal sequences comes about because there are more lexical entries with legal than illegal sequences. Because all lexical entries are activated when they match the speech input, there will be more top-down activation of phonemes that result in legal sequences (e.g., $/ r$ /given a preceding $/ t /$ ) than illegal ones (e.g., /l/ given a preceding $/ t /$ ), biasing perception of legal clusters (e.g., /tr/). By being sensitive to the frequency with which clusters occur in the language, TRACE mimics what looks like the operation of a phonotactic rule.

The present investigation explored the perception of phonotactically illegal sequences with the aim of developing a deeper understanding of phonological influences in speech processing. In addition to addressing the cause of the phonotactic context effect, the influence of two other forms of phonological information on the perception of illegal clusters was investigated-rules of syllabification (Experiment 2) and vowel epenthesis (Experiment 3).

\section{EXPERIMENT 1}

In a frequency-based explanation of the phonotactic context effect, the size of the effect should correlate positively with the difference between the frequencies of pairs of clusters (e.g., $/ \mathrm{tr} / \mathrm{vs}$. $/ \mathrm{tl} /$ ). As the size of the difference increases, so should the context effect. Furthermore, this should hold true for any pair of clusters, not just those that are illegal. A strictly rule-based phonological account might not show sensitivity to variation in the frequency of a cluster, but only to whether the cluster is legal. In this case, phonotactic effects should be found only for illegal clusters and be similar in magnitude.

When Massaro and Cohen's (1983) data are examined with these predictions in mind, neither account is sufficient to explain the results. Although the /s/ and / $\mathrm{t} / \mathrm{con}$ texts yielded labeling shifts of similar size, supporting the claims of a phonological account, the /d/ context produced a very small effect, a finding difficult to explain by a rule-based explanation.

To assess the accuracy of the frequency account, the frequencies with which the $/ \mathrm{d} /, / \mathrm{s} /$, and $/ \mathrm{t} /$ clusters occur in an on-line, phonologically transcribed version of $\mathrm{Ku}$ čera and Francis (1967) were calculated and are shown on the left side of the top graph in Figure 1. The counts are independent of where in the word the cluster occurred (e.g., initially, medially) because a frequency explanation might not be sensitive to such information (e.g., the TRACE model). If the differences between the /1/ 

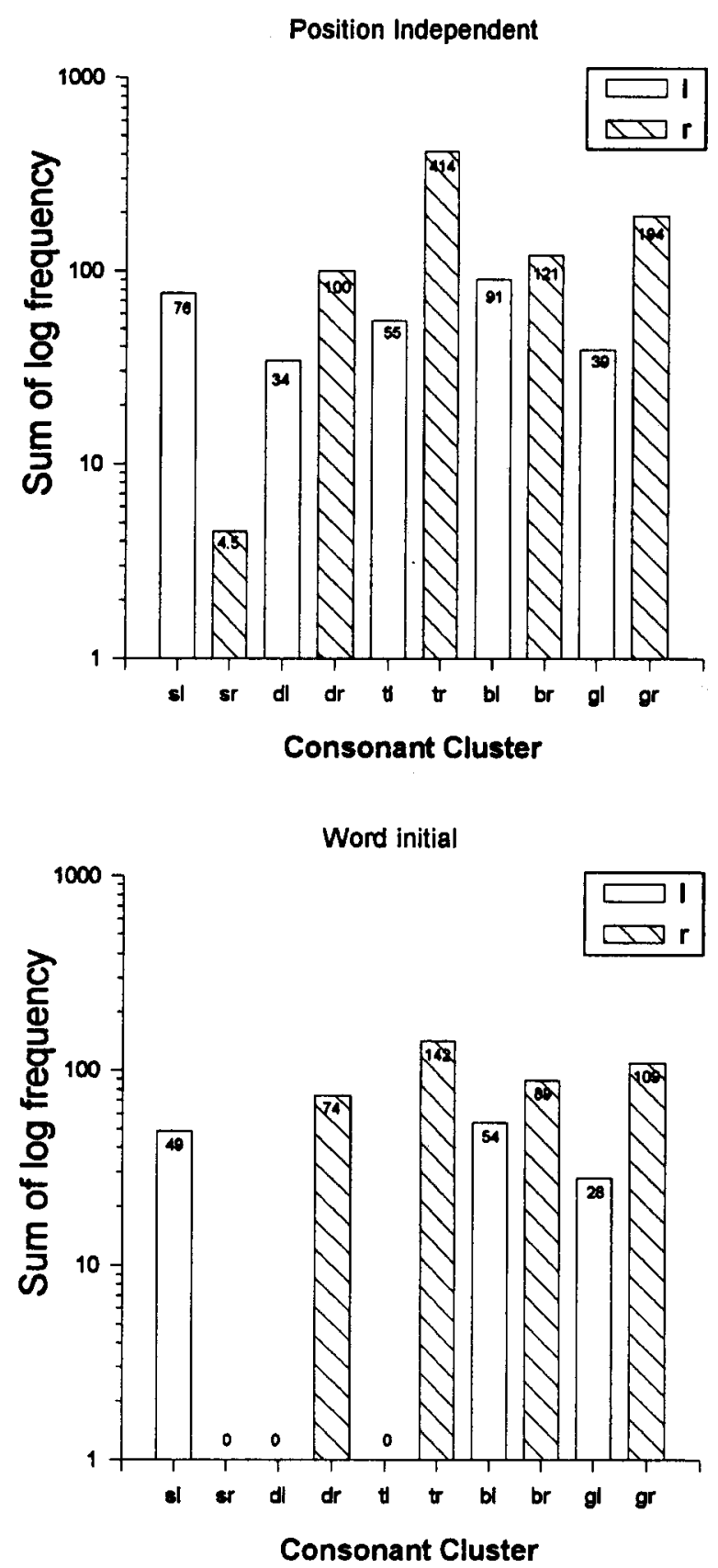

Figure 1. Frequency with which the obstruent-liquid clusters used in Experiment 1 occur in Kučera and Francis (1967). The top graph contains counts (actual values are printed inside each bar) independent of cluster position within a word. Counts in the bottom graph are based on occurrences in word-initial position only.

and $/ \mathbf{r} /$ counts for each context are compared, the predicted ordering of effect sizes in Massaro and Cohen's (1983) data should have been $/ t />/ s />/ d /$, with $/ t /$ being much larger than $/ \mathrm{s} /$, and $/ \mathrm{s} /$ being only slightly larger than $/ \mathrm{d} /$. Massaro and Cohen found $/ \mathrm{t} / \approx / \mathrm{s} />/ \mathrm{d} /$. Although $/ \mathrm{d} /$ was indeed smallest, the differences in effect size between contexts were not correctly predicted.
If the predictions of the frequency account are based on word-initial occurrences of clusters only (bottom graph in Figure 1), the frequency account fares even worse. The predicted ordering of effect sizes is $/ \mathrm{t} />/ \mathrm{d} />/ \mathrm{s} /$. Note that $/ \mathrm{s} /$ and $/ \mathrm{d} /$ are in the reverse ordering of what was found.

Experiment 1 was undertaken to explore further the viability of these two accounts. Liquid labeling was assessed across multiple contexts in which the two accounts make contrasting predictions. The three illegal contexts that were used by Massaro and Cohen (1983; Experiments 1 and 3 ) were combined with a $/ g /$ context, which provided a means of dissociating phonotactic legality from cluster frequency. Both endpoints in the $/ g /$ context (e.g., $/ \mathrm{gl} /, / \mathrm{gr} /$ ) are legal, but the $/ \mathrm{r} /$ context is more frequent than the /1/ (see Figure 1). In fact, the magnitude of this difference (155, using the positionindependent tallies) is larger than that for both the /d/ and /s/ contexts ( 66 and 72 , respectively), so a large labeling bias should be present in the $/ \mathrm{g} /$ context. More precisely, a frequency account predicts that effect sizes should order as follows: $/ \mathrm{t} />/ \mathrm{g} />/ \mathrm{s} />/ \mathrm{d} /$. Predictions based on the word-initial tallies change only for $/ \mathrm{d} /$ and $/ \mathrm{s} /$, which swap places: $/ \mathbf{t} />/ \mathbf{g} />/ \mathrm{d} />/ \mathrm{s} / .{ }^{1}$ Because the word-initial and position-independent tallies yielded similar predictions, the frequency-based predictions will be discussed in terms of the position-independent tallies only.

$\mathrm{A} / \mathrm{b} /$ context served as a baseline from which effect sizes in the other contexts were measured. It was the only pair of stop-liquid clusters for which both clusters are similar in frequency. The slightly higher occurrence of $/ \mathrm{br} /$ might diminish the magnitude of phonotactic effects at the / $/$ endpoint, but this should have an equal effect in all $/ \mathrm{r} /$-biased contexts.

The $/ g /$ context also provides a useful test of the phonology account; $/ g /$ was selected because it exhibits the largest frequency difference among stop-liquid clusters in which both liquids are legal continuations. Yet the phonology account predicts that no labeling bias should be found in this condition. The account again predicts phonotactic effects of similar magnitude in those contexts that have an endpoint that is phonotactically illegal (i.e., /d/, $/ \mathrm{s} /, / \mathrm{t} /)$.

\section{Method}

Participants. Thirty-one Ohio State University undergraduates, all native speakers of American English, participated in exchange for course credit. None reported hearing difficulties.

Stimuli. The Klatt (1980) synthesizer was used to create the obstruent-liquid-vowel continua. The vowel $/ \mathfrak{a} /$ was chosen to avoid the creation of English words. The $F 1-F 3$ center frequencies were 711,1743 , and $2472 \mathrm{~Hz}$, respectively.

For the context phoneme to influence liquid labeling, it was necessary to create a liquid continuum whose endpoints were not labeled as their respective categories $100 \%$ of the time while at the same time a clear and systematic change in labeling could be obtained across the continuum. Both spectral and temporal characteristics of the liquid were varied in continuum creation. An eight-step $/ \mathrm{r} /-/ / /$ continuum was constructed using parameters listed in Massaro and Cohen (1983) and Samuel (1989) as guides. The primary parameter that varied was the $F 3$ transition, which for the $/ r /$ endpoint remained steady at $1752 \mathrm{~Hz}$ for $100 \mathrm{msec}$ and then transi- 
tioned to $2472 \mathrm{~Hz}$ over the next $100 \mathrm{msec}$. For the / / / endpoint, $F 3$ fell from $3173 \mathrm{~Hz}$ to $2472 \mathrm{~Hz}$ over the initial $250 \mathrm{msec} . F 1$ and $F 2$ followed a parallel trajectory at each endpoint. At the $/ \mathbf{r} /$ endpoint, they remained constant for $50 \mathrm{msec}(474 \mathrm{~Hz}, 900 \mathrm{~Hz})$ and then transitioned into the vowel formants over the next $100 \mathrm{msec}$. At the /1/ endpoint, they remained constant for $100 \mathrm{msec}$ and then transitioned into the vowel formants over the next $50 \mathrm{msec}$. The six middle steps of the continuum were created by interpolating between these endpoint values in equal-sized steps. The fundamental frequency began at $160 \mathrm{~Hz}$ and dropped to $152 \mathrm{~Hz}$ by the end of the syllable. Voicing amplitude (AV) remained constant at 54 over the liquid and vowel, ramping to zero over the final $35 \mathrm{msec}$.

Steps on the $/ \mathrm{b} /, / \mathrm{d} /, / \mathrm{g} /$, and $/ \mathrm{t} /$ context continua were all $460 \mathrm{msec}$ long. /b/ was synthesized with $50-\mathrm{msec}$ formant transitions that began at $158 \mathrm{~Hz}$ for $F 1$ and at $1100 \mathrm{~Hz}$ for $F 2$. Voicing amplitude went from 50 to 60 over the first $10 \mathrm{msec}$ before dropping to 54 over the next $10 \mathrm{msec}$. Frication amplitude (AF) decreased from 52 to 0 over then initial 5 msec. Bypass path amplitude $(A B)$ increased from 0 to 53 during the initial $5 \mathrm{msec}$ and then remained constant for $45 \mathrm{msec}$ before dropping to zero over the next $5 \mathrm{msec}$. Formant transitions for $/ \mathrm{d} /$ were $55 \mathrm{msec}$ long with $F 1$ and $F 2$ starting frequencies of 211 and $1600 \mathrm{~Hz}$. AV (54) began $15 \mathrm{msec}$ after syllable onset. Frication increased from 20 to 50 over the first $10 \mathrm{msec}$ and then dropped to 0 by $45 \mathrm{msec}$. $/ \mathrm{g} /$ formant transitions were $65 \mathrm{msec}$ long, with $F 1$ and $F 2$ starting frequencies of 238 and $1732 \mathrm{~Hz}$. AV increased from 0 to 58 over $5 \mathrm{msec}$ beginning $15 \mathrm{msec}$ after syllable onset. AF decreased from 60 to 0 over the first $20 \mathrm{msec}$. Formant transitions for $/ \mathrm{t} /$ were $65 \mathrm{msec}$ long. $F 1$ and $F 2$ started at 378 and $1700 \mathrm{~Hz}$. Voicing began $60 \mathrm{msec}$ after syllable onset, rising from 0 to 54 in $5 \mathrm{msec}$. Frication amplitude was 60 at syllable onset and dropped to 0 by $50 \mathrm{msec}$. Aspiration amplitude was 30 at syllable onset, rose to 68 by $35 \mathrm{msec}$, and dropped to 0 by $65 \mathrm{msec}$.

Continuum steps in the $/ \mathrm{s} /$ context were $660 \mathrm{msec}$ long. There were no formant transitions into the liquid. AV rose from 0 to 54 during the first $235 \mathrm{msec}$ of the syllable. AF rose from 0 to 54 during the first $40 \mathrm{msec}$, remained constant for $150 \mathrm{msec}$, and then dropped to 0 over the next $40 \mathrm{msec}$. The amplitude of $F 6$ was 64 for the first $20 \mathrm{msec}$, dropped to 60 for $145 \mathrm{msec}$, and then dropped to 0 over the next $50 \mathrm{msec}$.

The quality of the synthetic obstruents was assessed in a pilot experiment. Thirteen listeners categorized each obstruent embedded in the CCV context (legal continuum endpoints only) as one of five possible consonants 24 times. Fricative categorization was perfect. Stop categorization averaged $87 \%$ correct (range, $81 \%-93 \%$ ), with $50 \%$ of the errors being made by 2 or 3 participants. Errors were not systematic across stops.

Extensive pilot testing with the full set of experimental materials was necessary to identify $/ \mathrm{r} /$ and $/ 1 /$ endpoint tokens that were sufficiently perceptually ambiguous to show phonotactic influences. When the $/ r /-/ 1 /$ continuum was presented without a preceding obstruent in a liquid categorization task, the parameter values that were eventually selected yielded $/ \mathrm{r} /$ categorization responses of $89 \%$ for the $/ \mathrm{r}$ / endpoint and $26 \%$ for the $/ 1 /$ endpoint (context effects failed to emerge with more extreme endpoint values). The difference in endpoint clarity (14\%) might result in a slight underestimation of the size of the /s/ context effect on liquid labeling relative to the other context phonemes. As will be seen, the /s/ context effect was very robust, suggesting that the difference in endpoint clarity probably had minimal influence on the outcome of the experiment.

Equipment. Stimuli were synthesized at a $10-\mathrm{kHz}$ sampling rate (12-bit resolution) and stored on hard disk. A microcomputer controlled stimulus presentation and response collection. Stimuli were low-pass filtered at $4.8 \mathrm{kHz}$ before being amplified and presented to participants over headphones. Responses were collected using a four-button response box, with the left and right index and middle fingers pressing the buttons.
Procedure. Listeners were tested in groups of 4 or fewer, with each in a separate sound-attenuated cubicle. The experiment began with a familiarization session in which participants listened to examples of synthetic speech and to the endpoints of the continuum. In the test session, participants were instructed to classify the liquid in the syllable as belonging to one of four categories. Descriptions of the categories were printed above the four response buttons. Moving from one side of the response box to the other, the labels were "sure l", "somewhat sure l", "somewhat sure r", and "sure r." Four response choices were provided rather than two in an effort to increase the sensitivity of measuring differences between contexts.

Each step on each of the five continua was presented 16 times for a total of 640 trials. Listeners were tested in two sessions that were separated by 2 days. In each, there were four test blocks of 80 randomly ordered trials, with each stimulus presented twice in a block. A 1.4-sec pause separated trials, and there was a 3-sec timeout after stimulus presentation. A rest break was provided at the end of Block 2. Twenty-four practice trials preceded the test session.

\section{Results}

Responses in the four categories were converted into numerical values, with "sure l" coded as 0 and "sure $r$ " coded as 3 . For each listener, a mean response score was calculated for each step on all continua. Listeners' responses were then averaged and are plotted in Figure 2 as a function of the preceding context. Data in the $/ b /$ context are represented with a dashed line. Contexts that were predicted by either account to yield an $/ \mathrm{r} /$ bias $(/ \mathrm{d} /$, $/ \mathrm{g} /, / \mathrm{t} / \mathrm{l})$ are represented by filled symbols. The one context predicted to show an $/ 1 /$ bias $(/ / \mathrm{s} /)$ is represented by an open symbol.

With the $/ \mathrm{b}$ / function as a reference, inspection of the figure shows that phonotactic context effects of differing magnitudes were found. At the $/ \mathbf{r} /$ endpoint, the $/ \mathrm{s} /$ function falls far below the $/ \mathrm{b} /$ function, indicating that the endpoint steps were heard far less often as $/ \mathbf{r} /$. Just the opposite pattern is present with the / $/$ / context at the / $/$ /

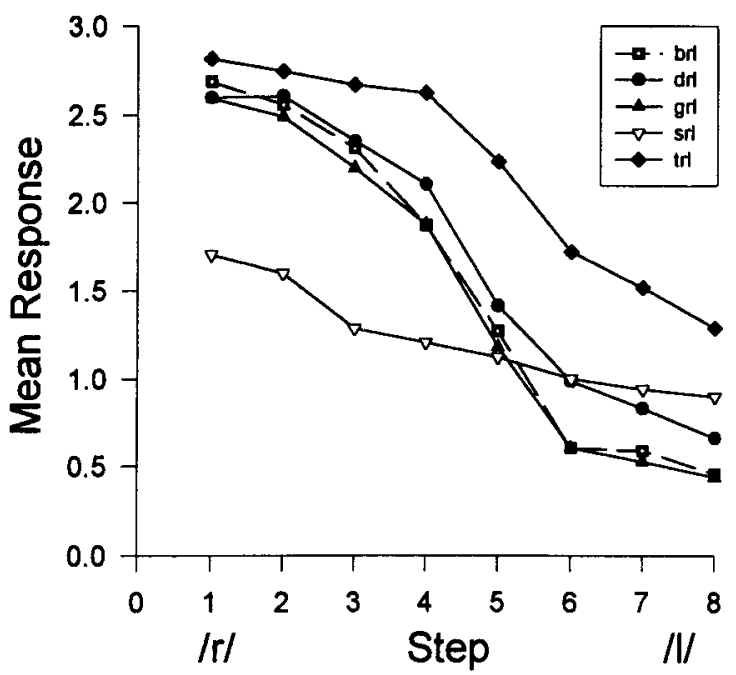

Figure 2. Mean $/ \mathbf{r} /-/ 1 /$ labeling responses as a function of obstruent context in Experiment 1 (clusters occurred word initially). 
endpoint. Here the $/ \mathrm{t} /$ function is raised far above the $/ \mathrm{b} /$ function, indicating that the endpoint steps were frequently heard as $/ r /$. A smaller bias to label the /l/ endpoints as $/ r /$ is present in the $/ d /$ context. No labeling bias was found in the $/ g$ / context; the $/ g$ / function closely overlaps the $/ \mathrm{b}$ / function across the entire $/ \mathrm{r} /-/ 1 /$ continuum.

The size of the context effects were measured by averaging labeling scores across the three steps at each endpoint of a function $(1,2,3$ or $6,7,8)$ and then subtracting this value from that in the baseline condition at the corresponding endpoint (see Pitt \& Samuel, 1993; Samuel \& Kat, 1996, for similar procedures). Statistical analyses were carried out separately for each context and then compared across contexts. In the $/ \mathrm{s} /$ context, responses to Steps 1-3 were on the average $33 \%$ lower than those in the $/ b /$ context. This large context effect for $/ \mathrm{s} /$ was statistically reliable $[F(1,30)=71.76, p<.001]$. The effect for the $/ \mathrm{t} /$ context (comparison of the $/ \mathrm{b} /$ and $/ \mathrm{t} /$ functions over Steps 6-8) was almost identical in magnitude $[32 \%, F(1,30)=40.78, p<.001]$ and did not differ reliably from the $/ \mathrm{s} /$ context. The $/ \mathrm{d} /$ context produced a reliable shift, although it was less than a third the size of that found in the $/ \mathrm{t} /$ and $/ \mathrm{s} /$ contexts $[9 \%, F(1,30)=9.85, p<$ $.04]$. This drop in effect size was reliable in both the $/ t /$ and $/ \mathrm{s} /$ comparisons. The effect was less than $1 \%$ in the $/ g /$ context, which differed reliably from all other contexts.

\section{Discussion}

The results provide little support for a frequency-based account of the phonotactic context effect, which predicted an effect size ordering of $/ \mathrm{t} />/ \mathrm{g} />/ \mathrm{s} />/ \mathrm{d} /$. What was obtained was $/ \mathrm{s} / \approx / \mathrm{t} />/ \mathrm{d} />/ \mathrm{g} /$. If the frequency account were correct, there should have been a strong positive correlation between the size of the phonotactic effect in each context and the size of the difference in $/ \mathrm{r} /$ and $/ 1 /$ frequency counts in each context (Figure 1). Although positive, the correlation was quite weak $(r=.15)$. Perhaps most damaging to the frequency account was the failure to find any hint of an effect in the $/ g /$ context, where a large one was expected given the much more frequent occurrence in English of $/ \mathrm{gr} /$ than $/ \mathrm{gl} /$. To the extent that these data provide evidence against a frequency account, they are also damaging to models in which a frequencysensitive mechanism is solely responsible for the effect (e.g., TRACE; see Gaskell \& Marslen-Wilson, 1996, for a related discussion).

An explanation based on rules of phonotactic permissibility fairs somewhat better. It successfully predicts that the phonotactic bias should be found only with illegal clusters $(/ \mathrm{dl} /, / \mathrm{sr} /, / \mathrm{tl} /)$, not legal ones. It comes up short only in not accounting for the smaller effect found with $/ \mathrm{d} /$ than with $/ \mathrm{s} /$ and $/ \mathrm{t} /$. Some factor other than phonotactic permissibility may modulate phonological influences.

One possibility, which is also phonologically based, centers on a consideration of the memory representation of phonemes and how this might affect processing. Marslen-
Wilson and colleagues (Gaskell \& Marslen-Wilson, 1996; Lahiri \& Marslen-Wilson, 1991) have suggested that lexical representations of words are underspecified, with entries containing the fewest number of features necessary to specify a word. If it is assumed that the least specified phonemes yield the largest contextual influences, a radical underspecification framework (see Steriade, 1995) can also explain the differences in effect size found among context phonemes. $/ \mathrm{s} /$ and $/ \mathrm{t} /$ are the most unspecified phonemes (in both place of articulation and voicing) and showed similar effects. /d/ is less so (only place is unspecified), and it showed the smallest effect.

An alternative account of the differing labeling biases is based on the frequency of the context phonemes themselves, without consideration of the following liquid. Using a paradigm similar to that of the present experiment, Newman, Sawusch, and Luce (in press; see also Newman, Sawusch, \& Luce, 1997) found that a labeling bias, which was caused by the size of the lexical neighborhood of an utterance, was affected by the frequency of the tobe-categorized phonemes. Specifically, smaller labeling shifts were found with frequent phonemes such as $/ t /$ and $/ \mathrm{s} /$, as compared with $/ \mathrm{d} /$, which is far less frequent. The data in the present experiment ordered similarly, with more frequent phonemes having larger effects on processing. If this account of the differences in effect size is correct, both phonological and frequency-based processes are responsible for the phonotactic context effect.

The predictions of a lexical neighborhood account of the present results were also assessed because differences in the size of the neighborhoods of the continuum endpoints (e.g., /træ/ vs./tlæ/) might have correlated with the obtained ordering of effect sizes. Following Newman et al. (1997; see also Luce, Pisoni, \& Goldinger, 1990), a neighborhood was defined as those words that differed from an endpoint $\mathrm{CCV}$ by the addition, deletion, or substitution of a single phoneme. The Kučera and Francis (1967) database was used as the source for the words. No other restrictions on neighborhood membership (e.g., familiarity ratings) were imposed.

As with the frequency-based account, the size of the context effect was assumed to be a function of the size of the difference, within a continuum, in the sum of the log frequency of the words in the neighborhoods of the endpoints. The account predicted an effect size ordering of $/ \mathrm{t} />/ \mathrm{d} />/ \mathrm{s} />/ \mathrm{g} /$, which fails on a couple of key predictions. /d/ was expected to yield a slightly larger effect than $/ \mathrm{s} /$, when one substantially smaller than /s/ was obtained. $/ t /$ was expected to produce an effect substantially larger than $/ \mathrm{s} /$, when in fact they were almost identical. Also, $/ g /$ should have produced an $/ \mathrm{r} /$ bias, when none was found. Like the frequency-based approach, a neighborhood explanation does not provide a good account of the data.

\section{EXPERIMENT 2}

If listeners' knowledge of English phonotactics was the primary cause of the labeling bias in Experiment 1, then 
other forms of phonological information might also affect the emergence of the phonotactic context effect. This idea was explored in Experiment 2 by testing whether similar labeling biases are obtained when clusters occur word medially.

Although clusters such as $/ \mathrm{tl} /$ and $/ \mathrm{dl} /$ do not form the onsets of words, they do occur in the middle of multisyllabic words (e.g., Atlantic, maudlin). Phonotactic illegality is avoided in these instances by syllabifying the words so that the initial consonant is placed in the coda of the first syllable and the liquid is placed in the onset of the following syllable (e.g., At-lantic, maud-lin). Treiman and Zukowski (1990; see also Treiman \& Danis, 1988) showed that listeners apply this rule and others when syllabifying strings. For example, listeners virtually always syllabified words with medial clusters such as / $\mathrm{tl} /$ and / $\mathrm{dl} /$ between the stop and liquid, whereas legal clusters were frequently placed in the onset of the second syllable (e.g., a-pron, Ma-drid). Such outcomes are most readily explained by assuming that rules of English phonotactics are applied during syllabification.

One particularly intriguing aspect of these findings is that syllabification of words such as Atlantic is not what would be expected on the basis of an analysis of its acoustic realization. The consonant closure duration preceding burst release provides an obvious point at which to divide the word so that the illegal cluster is perceived in the onset of the second syllable (e.g., A-tlantic). The fact that the stop consonant can be heavily coarticulated with the liquid reinforces such an organization. Yet rules of syllabification are applied during processing that undo this organization and place the stop and the liquid in separate syllables.

During speech processing, does this powerful phonotactic rule of syllabification take precedence over that responsible for the phonotactic context effect? If so, the consonants of a word-medial illegal cluster would be perceived as belonging to different syllables before knowledge of phonotactic legality could affect liquid processing; the context effects observed in Experiment 1 should disappear or at least diminish in magnitude. That is, all labeling functions should overlap the $/ \mathrm{b} /$ function across the entire continuum. If large labeling biases are still found, it would be likely that local (e.g., phonotactic) influences take priority in processing, with syllabification rules being applied later.

\section{Method}

Participants. Twenty-eight new listeners from the same population as Experiment 1 participated.

Stimuli. To create disyllabic strings, the syllable / $m æ /$ was synthesized and prepended to all of the stimuli of Experiment 1, except for the $/ g /$ context continuum, which was dropped from the design because it yielded no context effect. $/ \mathrm{mæ} /$ was chosen because no English words were formed when combined with the CCVs of Experiment 1

/mæ/ was $320 \mathrm{msec}$ long with the formant frequencies of the vowel identical to those of the vowel in Experiment 1. Transitions for $F 2$ and $F 3$ were $80 \mathrm{msec}$, with $F 2$ and $F 3$ starting frequencies of 1243 and $2030 \mathrm{~Hz} . F 1$ began at $711 \mathrm{~Hz}$, and from $80 \mathrm{msec}$ to syllable offset it fell steadily to $692 \mathrm{~Hz}$. $F 0$ remained constant at
$160 \mathrm{~Hz}$. The nasal zero frequency began at $450 \mathrm{~Hz}$ at syllable onset, and at $80 \mathrm{msec}$ it steadily dropped to $280 \mathrm{~Hz}$ by syllable offset.

The acoustic realization of a consonant can change depending on the context in which it is spoken. Of the four obstruents used, /t/ would likely undergo the most variation when produced in medial versus initial positions. Aspiration, a cue to identification, is present when $/ t /$ occurs initially, but absent or greatly reduced when it occurs medially. / $\mathrm{t} /$ was not resynthesized to take this change into account, however. Although failing to do so might have made the stimuli mildly artificial, I felt that it was more important to hold the stimuli constant across Experiments 1 and 2 so that the manipulation of interest could be assessed without there also being changes in stimulus characteristics.

Because other phonological characteristics of speech can affect syllabification (e.g., word stress, vowel tenseness; see Treiman \& Danis, 1988), two pilot experiments were run to understand the stimulus conditions in which the labeling results were found. In the first, the endpoints of each continuum were presented to 13 listeners who had to repeat each disyllable, but with the order of the syllables reversed (e.g., mabla $\rightarrow$ blama). Of interest was whether the illegal stop-liquid clusters would split apart (e.g., matla $\rightarrow$ lamat) or remain intact and form the onset of the first syllable (e.g., matla $\rightarrow$ tlama). Listeners showed a clear preference for placing the consonants in separate syllables than in the onset of the first syllable ( $66 \%$ vs. $34 \%$, respectively). That phonological processes influenced syllabification of the synthetic disyllables suggests that these stimuli are processed in a manner similar to that of naturally spoken utterances.

The results of a second pilot experiment, in which 16 listeners classified the continua endpoints as receiving primary stress on the first or second syllable, indicated that the disyllables were very nearly neutrally stressed. Responses averaged $57 \%$ (50\% was perfect neutrality), a slight bias toward hearing the stimuli as being stressed on the second syllable.

Procedure. Pretesting indicated that a four-choice task did not yield data that were noticeably different from a two-choice task, so the latter was used. One response button was labeled "r," the other "l." The remaining methodological details were identical to those of Experiment 1.

\section{Results and Discussion}

Proportion of $/ \mathrm{r} /$ responses was calculated for each participant across all continua. The aggregate listener data are shown in Figure 3 as a function of context. With the exception of the $/ \mathrm{d} /$ context, the data resemble those of Experiment 1 . The $/ \mathrm{s} /$ context produced the smallest proportion of $/ \mathrm{r} /$ responses at the $/ \mathrm{r} /$ endpoint $[22 \%$ effect, $F(1,27)=4.10, p<.05]$, and the $/ \mathrm{t} /$ context produced the largest proportion of $/ \mathrm{r} /$ responses at the $/ 1 /$ endpoint $[17 \%$ effect, $F(1,27)=2.95, p<.10]$. In comparison with the corresponding contexts of Experiment 1, these two outcomes represent drops in effect size of $33 \%$ and $47 \%$, respectively.

Although these data suggest that effects of phonotactic legality were weaker when the clusters occurred medially, other aspects of the results were unexpected and indicate that a pooled analysis of listeners' data obscured the true nature of phonotactic influences. To begin with, instead of the $/ d /$ function rising slightly above the $/ b /$ function, as was found in Experiment 1, it dropped below the /b/ function over most of the continuum $(-7 \%$ reversal). Also, compared with Experiment 1, labeling functions were shallower and variability among listeners 


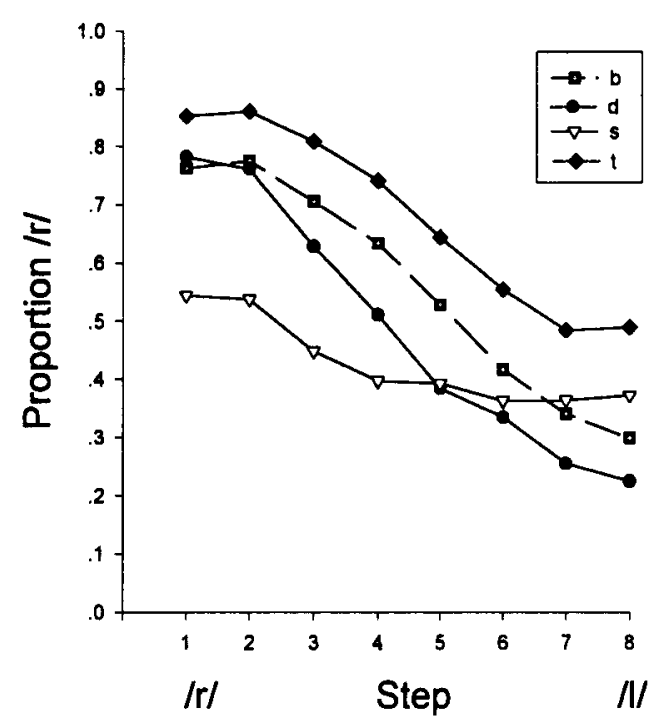

Figure 3. Mean proportion $/ \mathbf{r} /$ responses as a function of obstruent context in Experiment 2 (clusters occurred word medially).

was almost twice as great (Experiment $1, S D=.17$; Experiment $2, S D=.31$ ). The latter difference is a likely explanation for the statistically nonreliable phonotactic effect in the $/ \mathrm{t} /$ context.

Closer inspection of the labeling functions among participants revealed three categories of response patterns: Responses never fell below .5 across the continuum (/r/dominant responders); responses never rose above $.5(/ 1 /$ dominant responders); responses crossed .5 , ranging from at least .8 to $.3(/ \mathrm{r} /+/ 1 /$ responders $)$. When each listener's data were grouped by this classification, a clearer picture of phonotactic context effects emerged. The data are shown in the top part of Table 1. Listed in each cell is the number of listeners whose data fell into one of the three categories. $^{2}$

In the /b/ context, 17 of 28 listeners heard the continuum change from $/ \mathrm{r} /$ to $/ 1 /$. Six listeners heard it primarily as $/ r /$ and five as $/ 1 /$. A similar outcome was obtained in the $/ d /$ context. Eighteen listeners produced full functions, and there was a slight $/ \mathrm{r} /$ bias for a majority of the remaining listeners.

Large phonotactic effects were obtained in the $/ \mathrm{s} /$ and $/ \mathrm{t} /$ contexts. These effects were present in the $/ \mathrm{r} /$-dominant and / / -dominant functions. When the context was $/ t /, 15$ listeners' data fell into the $/ \mathrm{r} /$-dominant category, whereas the data from only 2 fell into the $/ 1 /$-dominant category. Just the reverse of this was obtained in the $/ \mathrm{s} /$ context, where there were $12 / 1 /$-dominant listeners but just $4 / \mathrm{r} /$-dominant listeners. Chi-square tests were performed to assess whether the patterns of classification differed from chance. None reached significance in the $/ \mathrm{b} /$ and $/ \mathrm{d} /$ contexts. In the $/ \mathrm{s} /$ and $/ \mathbf{t} /$ contexts, reliable effects were obtained $\left[\chi^{2}=\right.$ $4.00, p<.05 ; \chi^{2}=9.94, p<.001$, respectively]. The interaction of/r/-dominant and /1/-dominant data across the $/ \mathrm{s} /$ and $/ \mathrm{t} /$ contexts was also reliable $\left[\chi^{2}=13.94, p<.001\right]$.
Even though a sizable phonotactic effect was obtained in the $/ \mathrm{s} /$ context, these data were noisier than in the other contexts. Seven listeners' functions were atypical and did not fall neatly into one of the three response categories (e.g., proportion $/ \mathbf{r} /$ was higher at the $/ 1 /$ than at the $/ \mathrm{r} /$ endpoint and fluctuated erratically above and below the endpoint values in the middle steps). Because it seemed inappropriate to place the data from these ambiguous responders into one of the three categories, their data were categorized separately.

Although the data from these ambiguous responders do not compromise the results, it is useful to point out that they are an exception to the rule. The results from the /s/ and $/ t /$ contexts in a similar experiment are shown in the bottom half of Table 1 . The only methodological difference from Experiment 2 was that the initial nasal was spliced off of all stimuli to examine whether variation in the syllabic structure of the initial syllable ( $V$ instead of (V) affected labeling. As can be seen, the results tell the same story, but more cleanly. In the $/ \mathrm{s} /$ context, there were 15 more $/ 1 /$-dominant than $/ \mathrm{r} /$-dominant listeners $\left(\chi^{2}=8.33, p<.001\right)$. In the $/ t /$ context, the opposite outcome was found, with 11 more $/ \mathrm{r} /$-dominant than $/ 1 /$ dominant listeners $\left[\chi^{2}=7.12, p<.001\right]$. The interaction across contexts was again reliable $\left[\chi^{2}=15.45, p<.001\right]$.

Whether examined overall or looked at more closely as a function of listener response pattern, phonotactic context effects were found word medially. The subanalysis revealed that massive effects were obtained in the $/ \mathrm{s} /$ and $/ t /$ contexts. Many listeners exhibited complete, not just partial, lifting and lowering of the functions at the illegal endpoints. Why larger effects were found medially than initially is likely due to the fact that liquid identification was more difficult word medially because of partial masking by the first syllable. The same reason, coupled with the fact that the liquid continuum had partially ambiguous endpoints, is also the most likely explanation for the wide variation in labeling among listeners in Experiment $2 .^{3}$ In experiments with unambiguous continuum endpoints, listeners typically produce much more similar and complete labeling functions.

The data obtained in the /d/ context are the most equivocal; the only evidence of phonotactic influences is that two more listeners were classified as $/ \mathrm{r} /$-dominant than

Table 1

Number of Listeners Whose Data Exhibited One of the Four Types of Labeling Functions in Each Phoneme Context

\begin{tabular}{lrrrr}
\hline & \multicolumn{4}{c}{ Context Phoneme } \\
\cline { 2 - 5 } Type of Labeling Function & $/ \mathrm{b} /$ & $/ \mathrm{d} /$ & $/ \mathrm{t} /$ & $\mathrm{s} /$ \\
\hline Experiment 2 & 6 & 6 & 15 & 4 \\
$/ \mathrm{r} /$ dominant & 5 & 4 & 2 & 12 \\
$/$ l dominant & 17 & 18 & 11 & 5 \\
$/ \mathrm{r} /+/ \mathrm{l} /$ & & & & 7 \\
Ambiguous $(/ \mathrm{s} /$ only) & & & 14 & 6 \\
Replication of Experiment 2 & & & 3 & 21 \\
$/ \mathrm{r} /$ dominant & & 13 & 3 \\
$/ \mathrm{l} /$ dominant & & &
\end{tabular}


/1/-dominant. Although the small effect is in keeping with what was found in Experiment 1, its virtual disappearance word medially might indicate that rules of syllabification had priority in processing. The robust phonotactic effects found in the $/ \mathrm{s} /$ and $/ \mathrm{t} /$ contexts provide strong evidence against this position, however, and suggest that rules of phonotactic permissibility were applied prior to rules of syllabification. Of course, it would be useful to assess the generality of the present results to disyllables that vary in ways that are known to affect syllabification (e.g., syllable of primary stress).

\section{EXPERIMENT 3}

The results of Experiments 1 and 2 suggest that knowledge of English phonotactics biases processing of liquids in illegal clusters so that they are heard as legal clusters. ${ }^{4}$ Another phonologically based method by which to make an illegal sequence legal is to insert a vowel between the two consonants (e.g., /tlae/ $\rightarrow /$ tolae/). This phenomenon, known as vowel epenthesis, can be heard in English if one attends closely to the pronunciation of the consonants of a cluster in exaggerated or slow speech. The initial consonant is often followed by a reduced vowel (e.g., schwa) to keep the utterance intact as a single word and can result in the perception of an additional syllable in the word (e.g., /greIt/ $\rightarrow$ /gareIt $/$ ).

Evidence suggesting that epenthesis is a phonological process operating during language processing can be found in loan words borrowed from other languages. For example, the Japanese language does not allow wordinitial consonant clusters. English loan words with such clusters are modified to conform to Japanese phonology by inserting a vowel between the consonants of the cluster (e.g., /straik/ $\rightarrow$ /sutoraiku/; see Takagi \& Mann, 1994).

Is vowel epenthesis another method by which phonotactic processes affect the perception of illegal clusters such as $/ \mathrm{sr} /$ and $/ \mathrm{tl} /$ ? This question was addressed in the final experiment. The endpoint steps of the $/ t /$ and $/ s /$ context continua $(/ \mathrm{sr} /, / \mathrm{sl} /, / \mathrm{tr} /, / \mathrm{tl} /)$ ) were presented to listeners, who had to judge whether the utterances had one or two syllables. The steady-state portion of the liquid was progressively lengthened in each of the four stimuli to create the impression of schwa emerging between the obstruent and liquid.

If epenthesis is another means by which the perceptual system biases processing of illegal clusters, then twosyllable responses should occur more often with illegal clusters (e.g., /sr/, /tl/) than legal clusters (e.g., /sl/, /tr/). Put another way, illegal clusters might be more fragile than legal ones in terms of the consonants forming a unitary percept, and thus more susceptible to epenthesis. No differences should be found as a function of legality if phonotactic processes do not function in this manner.

\section{Method}

Participants. Twenty-one new listeners from the same pool as the preceding experiments participated.
Stimuli. / $/$ and $/ \mathrm{t} /$ were used as the context phonemes because they produced the largest phonotactic effects in the preceding experiments. Two four-step continua were created with each context, one with $/ \mathbf{r} /$ and one with $/ \mathrm{l} /$. The synthesis parameters of the $/ \mathrm{sr} /, / \mathrm{sl} /, / \mathrm{tr} /$, and $/ \mathrm{tl} /$ endpoint tokens in Experiment 1 were used. The only change was that the $F 1-F 3$ steady-state portions that corresponded to the liquid were altered. For the two continua with $/ \mathrm{r}$, the one-syllable endpoints had $F 1-F 3$ steady-state durations of $80 \mathrm{msec}$. For the two continua with/l/, the one-syllable endpoints had $F 1-F 2$ durations of $130 \mathrm{msec}$, and an $F 3$ duration of $280 \mathrm{msec}$. Thirty msec were added to all of these values at each successive step, yielding a continuum whose endpoints differed by $90 \mathrm{msec}$. The range of values was selected based on piloting in which durational variation led to perceived changes in the number of syllables in the utterance. Syllable duration was $660 \mathrm{msec}$ and remained constant across steps. The identity of the liquid was not noticeably affected by lengthening the steady-state portion of the vowel, in large part because the $F 3$ formant transition, the primary cue to liquid identity, occurred after the steady-state portion. Perceptually, the steady-state portion sounded like /3r/.

Procedure. The procedure was similar to that of Experiment 1. Listeners were first introduced to synthetic speech and then instructed on the experimental task. Examples of one- and two-syllable words were provided to listeners to ensure that they understood which dimension to attend when categorizing the utterances as one or two syllables. No other instructions were provided on syllabification of the stimuli. One response button was labeled "one syllable," the other "two syllables." Two blocks of 160 randomly ordered trials were presented, with each step presented 10 times per block, for a total of 20 presentations per step. The pause between trials was $2 \mathrm{sec}$ and there was a 3 -sec timeout. The experiment was completed in one test session and there were eight practice trials.

\section{Results and Discussion}

Each listener's data were scored as the proportion of one-syllable responses to each step in each continuum. The averaged data are plotted in Figure 4 as a function of the four continua.

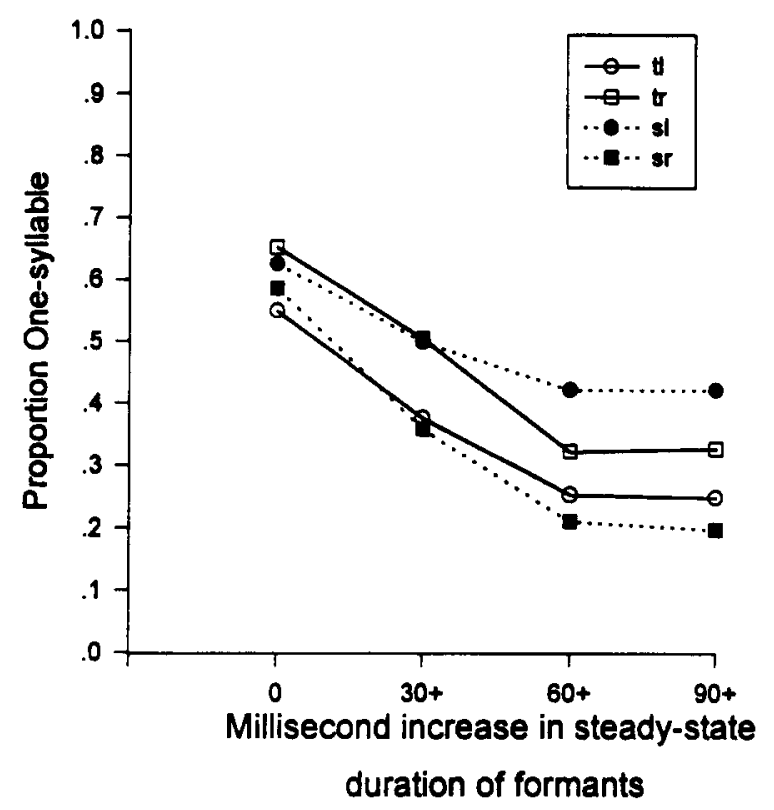

Figure 4. Mean proportion one-syllable responses as a function of context and steady-state duration of $F 1-F 3$. 
Overall, listeners tended to hear the stimuli as containing two syllables. Nevertheless, there was a bias toward labeling illegal clusters as being two syllables in length, and the bias held across the continuum. This outcome can be seen most easily by examining the data in each context separately. In the / $t /$ context (open symbols with unbroken lines), the /t1/ function is always below the / $\mathrm{tr} /$ function, indicating that utterances with the illegal cluster $(/ \mathrm{t} 1 /)$ were heard as containing two syllables more often than those with a legal cluster $(/ \mathrm{tr} /)$. Just the reverse occurred in the /s/ context (filled symbols with dotted lines), where the /sr/ function is always below the /sl/ function. /sr/ was heard as being two syllables in length more than its legal counterpart/sl/. A two-way analysis of variance with context and liquid as factors revealed that the interaction of the two variables was reliable, indicating that one-syllable responses to legal sequences $(/ \mathrm{sl} /, / \mathrm{tr} /)$ were reliably greater than those to illegal sequences $(/ \mathrm{sr} /$, $/ \mathrm{tl} /)[F(1,20)=6.75, p<.02]$.

The pattern of labeling differed in the two contexts. In the $/ t$ / context, the magnitude of the epenthesis effect varied minimally across the continuum (one-syllable responses to $/ \mathrm{tr} /$ were .7-.12 higher than to $/ \mathrm{tl} /$ ) and showed no systematic change in magnitude as formant duration increased. The interaction of liquid with formant duration was not reliable $[F(1,20)=1.85 p<.19]$. In the $/ \mathrm{s} /$ context, the size of the effect increased across the continuum, with one-syllable responses to /sl/ being .04 greater at the $0-\mathrm{msec}$ endpoint and .22 greater at the $90+\mathrm{msec}$ endpoint. This change in effect size was reliable $[F(1,20)$ $=3.75, p<.02]$. The three-way interaction of context, liquid, and formant duration did not reach significance.

These results provide another demonstration of how phonotactic knowledge can affect the perception of illegal sequences: There is a bias toward perceiving a vowel between the consonants of an illegal cluster. Functionally, the epenthesis effect may be no different from the phonotactic context effect. In both phenomena, the context phoneme alters how the following section of speech is perceived. Which effect is found in a given situation might depend, among other things, on the clarity of the speech signal. If the liquid is perceptually ambiguous, context would likely bias processing in favor of the phonotactically legal sequence. If the liquid is a clear token, context might not as easily alter the identity of the liquid. Instead, the utterance could be reinterpreted as having an additional (epenthetic) vowel.

\section{GENERAL DISCUSSION}

The findings of this study provide further evidence that knowledge of English phonology affects speech processing. This conclusion is based on the results of Experiments 1 and 3, which, when taken together, demonstrated that phonotactic knowledge affects phoneme processing in two ways. In Experiment 3, the frequency of vowel epenthesis was shown to be affected by knowledge of English phonotactics. The labeling biases observed in
Experiment 1 were better explained by an account based on listeners' knowledge of the permissible phoneme sequences in English than an account based on the frequency with which such sequences occur. The latter conclusion could be strengthened by generalizing the null result obtained with $/ g /$ to a much less frequent context phoneme that also exhibits a large $/ \mathrm{r} /$ or $/ 1 /$ bias and yields a continuum whose endpoints are phonotactically legal. Such a finding would demonstrate that the labeling bias is independent of the frequency of the context phoneme. Unless loan words are used, which pose other challenges, no such minimal pairs exist in English. It therefore seems prudent to use caution in generalizing the results beyond frequent context phonemes.

The present investigation also showed that syllabification processes had negligible effects on the phonotactic context effect (Experiment 2). Large labeling biases in favor of phonotactically legal sequences were obtained word medially, just as they were word initially.

When considered in the context of related work on phonological processing (Gaskell \& Marslen-Wilson, 1996; Treiman, 1989; Treiman \& Zukowski, 1990), an intriguing aspect of the present findings is that they suggest that the domain of influence (i.e., levels of representation) of phonotactic and syllabification processes are not the same. This claim is motivated by the failure to observe syllabification effects on liquid identification in Experiment 2, when such effects have been found repeatedly in other tasks (Treiman \& Danis, 1988; Treiman, Gross, \& Cwikiel-Glavin, 1992; Treiman \& Zukowski, 1990). If all phonological knowledge affected all stages of processing, then at a minimum there should have been a noticeable reduction in the magnitude of the phonotactic effect. Yet the subanalysis showed that many listeners exhibited very robust labeling biases, hearing the entire liquid continuum mostly as $/ \mathrm{r} /$ or $/ 1 /$ in illegal contexts.

As has been suggested for the application of rules of syllabification (Treiman \& Zukowski, 1990), there might be an order of precedence in the application of different classes of phonological knowledge. For example, those rules that operate on a local scale (e.g., adjacent phonemes) would be applied before those that operate on a more global scale (e.g., whole word). Such an ordering could maximize processing efficiency and potentially minimize competition between them. Local rules would operate early and on small segments of speech. Further support for this idea comes from a recent study by Halle, Segui, Frauenfelder, and Meunier (1998), who examined the earliness with which phonotactic influences manifest themselves during perception. They used a gating task in which French listeners heard progressively longer segments of the initial portion of illegal clusters (/dl/ and $/ \mathrm{tl} /$ ) that formed the onsets of two-syllable pseudowords. Within the first 100-150 msec of cluster onset (Gates 4-5), listeners' identification of the consonants as dentals steadily increased. After this point in time (Gate 5), identification as dentals began to drop and identification as phonotactically legal consonants (i.e., the velars $/ g$ / and 
$/ \mathbf{k} /$ ) increased. This reversal continued through the remaining gates. These findings suggest that phonotactic processes may begin to influence perception as early as $100 \mathrm{msec}$ after stimulus onset.

Global rules of phonological processing, such as those of syllabification, require larger chunks of the signal on which to operate, so they could do so reliably only later in recognition. Global processes might also reflect the application of a wider range of phonological information, which would explain why multiple phonological properties of a word (e.g., vowel tenseness, consonant class, word stress) interact to influence syllabification.

That different types of phonological knowledge might have separate domains of influence fits with what has been found in related literatures. Research in auditory word recognition suggests that semantic information does not affect prelexical processes or activation of lexical entries (Connine, 1987; Samuel, 1981, 1986), but it does affect lexical selection (Zwitserlood, 1989). Syntactic knowledge also has negligible effects on lexical activation (Tyler \& Wessels, 1983), but it is necessary for accurate sentence processing. Whether or not lexical knowledge affects processing at a prelexical level is more controversial (Cutler, Mehler, Norris, \& Segui, 1987; McQueen, 1991; Newman et al., in press; Pitt \& Samuel, 1995; Samuel, 1996). The selective influence of knowledge sources in processing may be so widespread that it should be considered a basic property of the language system.

\section{REFERENCES}

Altman, G. T. M., Garnham, A., \& Dennis, Y. (1992). Avoiding the garden path: Eye movements in context. Journal of Memory \& Language, 31, 685-712.

BOLAND, J. E. (1997). Resolving syntactic category ambiguities in discourse context: Probabilistic and discourse constraints. Journal of Memory \& Language, 36, 588-615.

Boland, J. E., \& Cutler, A. (1996). Interaction with autonomy: Multiple output models and the inadequacy of the great divide. Cognition, 58, 309-320.

Brown, R. W., \& Hildum, D. C. (1956). Expectancy and the perception of syllables. Language, 32, 411-419.

Church, K. W. (1987a). Phonological parsing and lexical retrieval. In U. H. Frauenfelder \& L. Komisarjevsky Tyler (Eds.), Spoken word recognition (pp. 53-69). Cambridge, MA: MIT Press.

ChURCH, K. W. (1987b). Phonological parsing in speech recognition. Boston: Kluwer.

ConNine, C. M. (1987). Constraints on interactive processes in auditory word recognition: The role of sentence context. Journal of Memory \& Language, 26, 527-538.

Connine, C. M., Blasko, D. G., \& Wang, J. (1994). Vertical similarity in spoken word recognition: Multiple lexical activation, individual differences, and the role of sentence context. Perception \& Psychophysics, 56, 624-636.

Cutler, A., Mehler, J., Norris, D., \& Segui, J. (1987). Phoneme identification and the lexicon. Cognitive Psychology, 19, 141-177.

CutTing, J. E. (1975). Aspects of phonological fusion. Journal of Experimental Psychology: Human Perception \& Performance, 104, 105-120.

Cutting, J. E., \& DAy, R. S. (1975). The perception of stop-liquid clusters in phonological fusion. Journal of Phonetics, 3, 99-113.

FLEGE, J. E., \& WANG, C. (1989). Native-language phonotactic con- straints affect how well Chinese subjects perceive the word-final English /t/-/d/ contrast. Journal of Phonetics, 17, 299-315.

FrauenFELDER, U. H., \& LAHIRI, A. (1989). Understanding words and word recognition: Does phonology help? In W. Marslen-Wilson (Ed.), Lexical representation and process (pp. 319-341). Cambridge, MA: MIT Press.

Frazier, L. (1987). Structure in auditory word recognition. In U. H. Frauenfelder \& L. Komisarjevsky Tyler (Eds.), Spoken word recognition (pp. 158-187). Cambridge, MA: MIT Press.

Gaskell, M. G., Hare, M., \& Marslen-Wilson, W. D. (1995). A connectionist model of phonological representation in speech perception. Cognitive Science, 19, 407-439.

Gaskell, M. G., \& Marslen-Wilson, W. D. (1996). Phonological variation and inference in lexical access. Journal of Experimental Psychology: Human Perception \& Performance, 22, 144-158.

Halle, P. A., Segui, J., Frauenfelder, U., \& Meunier, C. (1998). The processing of illegal consonant clusters: A case of perceptual assimilation? Journal of Experimental Psychology: Human Perception \& Performance, 24, 592-608.

JUSCZYK, P. W. (1995). Language acquisition: Speech sounds and the beginnings of phonology. In J. L. Miller \& P. D. Eimas (Eds.), Handbook of perception and cognition: Vol. 11. Speech, language, and communication (pp. 362-301). San Diego: Academic Press.

Jusczyk, P. W., Friederici, A. D., Wessels, J. M., Svenkerud, V. Y, \& JUSCZYK, A. M. (1993). Infants' sensitivity to the sound patterns of native language words. Journal of Memory \& Language, 32, 402420.

Jusczyk, P. W., LuCE, P. A., \& Charles-LuCE, J. (1994). Infants' sensitivity to phonotactic patterns in the native language. Journal of Memory \& Language, $33,630-645$.

KLATT, D. H. (1980). Software for a cascade/parallel formant synthesizer. Journal of the Acoustical Society of America, 67, 971-995.

KuČERA, H., \& FRANCIS, W. N. (1967). Computational analysis of presentday American English. Providence, RI: Brown University Press.

LAHIRI, A., \& MARSLEN-WILSON, W. D. (1991). The mental representation of lexical form: A phonological approach to the recognition lexicon. Cognition, 38, 245-294.

Luce, P. A., Pisoni, D. B., \& Goldinger, S. D. (1990). Similarity neighborhoods of spoken words. In G. T. M. Altmann (Ed.), Cognitive models of speech processing: Psycholinguistic and computational perspectives (pp. 122-147). Cambridge, MA: MIT Press.

MacDonald, M. C., Pearlmutter, N. J., \& Seidenberg, M. S. (1994). The lexical nature of syntactic ambiguity resolution. Psychological Review, 101, 676-703.

MANN, V. A., \& RePP, B. H. (1981). Influence of preceding fricative on stop consonant perception. Journal of the Acoustical Society of America, 69, 548-558.

Massaro, D. W. (1987). Speech perception by ear and eye: A paradigm for psychological inquiry. Hillsdale, $\mathrm{NJ}$ : Erlbaum.

Massaro, D. W. (1989). Testing between the TRACE model and the fuzzy logical model of speech perception. Cognitive Psychology, 21, 398-421.

Massaro, D. W., \& Cohen, M. M. (1983). Phonological context in speech perception. Perception \& Psychophysics, 34, 338-348.

MCCLELLAND, J. L. (1991). Stochastic interactive processes and the effect of context on perception. Cognitive Psychology, 23, 1-44.

MCClelland, J. L., \& Elman, J. L. (1986). The TRACE model of speech perception. Cognitive Psychology, 18, 1-86.

MCGURK, H., \& MACDONALD, J. (1976). Hearing lips and seeing voices. Nature, 264, 746-748.

MCQuEEN, J. M. (1991). The influence of the lexicon on phonetic categorization: Stimulus quality in word-final ambiguity. Journal of Experimental Psychology: Human Perception \& Performance, 17, 433-443.

Newman, R. S., Sawusch, J. R., \& Luce, P. A. (1997). Lexical neighborhood effects in phonetic processing. Journal of Experimental Psychology: Human Perception \& Performance, 23, 873-889.

Newman, R. S., Sawusch, J. R., \& LuCE, P. A. (in press). Underspecification and phoneme frequency in speech perception. In Papers in 
laboratory phonology (Vol. 5). Cambridge: Cambridge University Press.

Pitt, M. A., \& Samuel, A. G. (1993). An empirical and meta-analytic evaluation of the phoneme identification task. Journal of Experimental Psychology: Human Perception \& Performance, 19, 699-725.

PitT, M. A., \& SamUel, A. G. (1995). Lexical and sublexical feedback in auditory word recognition. Cognitive Psychology, 29, 149-188.

REPP, B. H., \& MANN, V. A. (1981). Perceptual assessment of fricativestop coarticulation. Journal of the Acoustical Society of America, 69 , 1154-1163.

Samuel, A. G. (1981). Phonemic restoration: Insights from a new methodology. Journal of Experimental Psychology: General, 110, 474-494.

Samuel, A. G. (1986). The role of the lexicon in speech perception. In E. C. Schwab \& H. C. Nusbaum (Eds.), Pattern recognition by humans and machines: Speech perception (Vol. 1, pp. 89-112). New York: Academic Press.

SAMUEL, A. G. (1989). Insights from a failure of selective adaptation: Syllable-initial and syllable-final consonants are different. Perception \& Psychophysics, 45, 485-493.

Samuel, A. G. (1996). Does lexical information influence the perceptual restoration of phonemes? Journal of Experimental Psychology: General, 125, 28-51.

Samuel, A. G., \& Kat, D. (1996). Early levels of analysis of speech. Journal of Experimental Psychology: Human Perception \& Performance, 22, 676-694.

STERIADE, D. (1995). Underspecification and markedness. In J. Goldsmith (Ed.), The handbook of phonological theory (pp. 114-174). Cambridge, MA: Blackwell.

TAKAGI, N., \& MANN, V. (1994). A perceptual basis for the systematic phonological correspondences between Japanese loan words and their English source words. Journal of Phonetics, 22, 343-356.

Treiman, R. (1989). The internal structure of the syllable. In G. Carlson \& M. Tannenhaus (Eds.), Linguistic structure in language processing (pp. 27-52). Dordrecht: D. Reidel.

Treiman, R., \& DANIS, C. (1988). Syllabification of intervocalic consonants. Journal of Memory \& Language, 27, 87-104.

Treiman, R., Gross, J., \& CWikiel-Glavin, A. (1992). The syllabification of /s/ clusters in English. Journal of Phonetics, 20, 383-402.

Treiman, R., \& ZuKowski, A. (1990). Toward an understanding of English syllabification. Journal of Memory \& Language, 29, 66-85.

TYLER, L. K., \& Wessels, J. (1983). Quantifying contextual contributions to word-recognition processes. Perception \& Psychophysics, 34, $409-420$.
ZwITSERLOOD, P. (1989). The locus of the effects of sentential-semantic context in spoken-word recognition. Cognition, 32, 25-64.

\section{NOTES}

1. These predictions were made using the sum of log frequency of the words in Kučera and Francis (1967) as the predictor because this measure includes information about word, and hence cluster, frequency and the number of words in which each cluster occurs. The same predictions (position independent and word initial) hold when based on either of these measures alone. Although the use of Kučera and Francis, a database of written English, to study the perception of spoken language might not be the preferred choice, this database is one of the only sources that provides information on cluster frequency that is sufficiently large to make meaningful predictions.

2. Graphs containing the full labeling functions from the subanalyses in Experiment 2 can be obtained from the author.

3. The subanalysis was also performed on the data of Experiment 1. Although fewer participants were classified as $/ r /$-dominant or $/ 1 /$. dominant in each context, the same pattern of results was found. In the $/ \mathrm{b} /$ context, only 1 listener did not produce a full labeling function, hearing the continuum mostly as $/ \mathbf{r} /$. In the $/ \mathbf{d} /$ context, 3 listeners were $/ \mathbf{r} /$-dominant, and none was $/ 1 /$-dominant. In the $/ t /$ context, the $/ r /$ bias was stronger, with $13 / \mathrm{r} /$-dominant listeners, and none as $/ 1 /$-dominant. This pattern reversed in the /s/ context, with $6 / \mathrm{r} /$-dominant and $10 / \mathrm{l} /$-dominant responders. The fact that half of the listeners in the /s/ context heard the continuum primarily as $/ \mathrm{r} /$ or $/ \mathrm{l} /$ also explains why the slope of the $/ \mathrm{s} /$ function is shallower than the others and why labeling at the /l/ endpoint was higher than that in the $/ \mathrm{b} /$ context, although not reliably.

4. In Experiments 1 and 2, obstruent identity was shown to affect liquid perception. The reverse can also occur, with liquid identity affecting obstruent perception. Massaro and Cohen (1983; Experiment 3) demonstrated this using the categorization paradigm. I found a similar result when listeners were asked to spell naturally spoken CCV syllables presented over headphones. The stop in phonotactically illegal clusters was frequently misheard as another stop with a different place of articulation (84 listeners were tested). Specifically, $/ \mathrm{d} /$ was heard as $/ \mathrm{g} / 67 \%$ of the time but as $/ \mathrm{b} /$ only $5 \%$ of the time. $/ \mathrm{t} /$ was reported as $/ \mathrm{k} / 13 \%$ and as $/ \mathrm{p} /$ $45 \%$ of the time. See Halle, Segui, Frauenfelder, and Meunier (1998) for related data.

(Manuscript received February 26, 1997; revision accepted for publication July 27,1997 .) 